\title{
CONCEITUAÇÃO E CONTABILIZAÇÃO DO CUSTO DE OPORTUNIDADE
}

\author{
Ilse Maria Beuren \\ Contadora. Mestre em Administração -UFRS e em Ciências Contábeis no ISEC/FGV. \\ Doutoranda em Contabilidade e Controladoria na FEA/USP. \\ Professora Assistente da UFSC.
}

\section{INTRODUÇÃO}

O objetivo do presente artigo consiste em analisar os principais conceitos de custo de oportunidade e a sua aplicabilidade no âmbito contábil.

Acredita—se que a aplicação do conceito de custo de oportunidade é de fundamental importância para que os relatórios contábeis possam ser mais úteis aos usuários da contabilidade.

A operacionalização adequada do conceito de custo de oportunidade na área contábil pode encontrar ampla aplicação especialmente como um instrumento de suporte nas decisões dos gestores das empresas.

Entretanto, o sistema contábil tradicional, quer com registros a valores históricos puros ou a valores históricos corrigidos, não contempla informações sobre os possíveis resultados na aplicação de recursos em utilizações alternativas. Por exemplo, se uma empresa aplica um montante de recursos em uma determinada alternativa de investimento, a Contabilidade não evidencia se o resultado auferido é inferior ou superior à aplicação deste mesmo montante de recursos em utilizações alternativas de investimento, com o mesmo nível de risco.

Um ponto que deve ser ressaltado é que a contabilização do custo de oportunidade não se limita apenas à sua importância na apuração do resultado econômico da empresa. A aplicação efetiva do conceito de custo de oportunidade na Contabilidade está, também, voltada a fornecer subsídios importantes para a avaliação de desempenho dos gestores, taxa de retorno nas decisões sobre investimentos, decisões do tipo comprar x fabricar, formação e acompanhamento do cálculo do preço de venda etc.

Nesse sentido, o presente artigo foi estruturado de modo a discutir, inicialmente, a abordagem econômica e contábil da conceituação do custo de oportunidade. Em seguida é enfocado o custo do capital. Finalmente, são apresentados alguns aspectos relacionados à operacionalização do custo, de oportunidade no âmbito contábil.

\section{CONCEITUAÇÃO ECONÔMICA DO CUSTO DE OPORTUNIDADE}

No contexto econômico, freqüentemente, o termo "custo de oportunidade" é substituído pelo termo "custo alternativo", como palavra sinônima.

Segundo BURCH \& HENRY ${ }^{1}$ o conceito de custo de oportunidade originou-se com Frederich Von Wieser (1851-1926). O conceito foi aplicado na determinação do valor dos fatores de produção. Ele definiu o valor de um fator de produção em qualquer situação como o seu custo de oportunidade, sendo tal custo de oportunidade definido como "a renda líquida gerada pelo fator em seu melhor uso alternativo".

\footnotetext{
1 BURCH, E. EarL \& NENBY, Miltf R. Oportunity and Incremental cost: attempt to define in systems terms: a
} commerry. The Accounting Review, 49(1): 118-123, January, 197k p. 119. 
Estes mesmos autores afirmam que, mais tarde, o conceito de custo de oportunidade foi difundido nos Estados Unidos pelo economista Herbert Joseph Davenport (1861-1931) no "The Economics of Enterprise".

Retornando ao conceito de custo de oportunidade apresentado, pode-se inferir que a expressão "em seu melhor uso alternativo" pressupõe a existência de duas ou mais alternativas viáveis.

Um outro aspecto relevante é que a opção de uma alternativa implica no abandono ou sacrifício da(s) não escolhida(s). Assim, o custo de oportunidade da alternativa escolhida é o custo da alternativa abandonada que Ihe proporcionaria maior satisfação.

No que concerne à aceitação do custo de oportunidade no processo de tomada de decisões, os economistas são concordes em que este é o verdadeiro custo.

Neste sentido, BILAS2 diz que "O custo dos fatores para uma empresa é igual aos valores destes mesmos fatores em seus melhores usos alternativos. Esta é a doutrina dos custos alternativos ou de oportunidade e é a que $\mathrm{O}$ economista aceita quando fala de custos de produção". Esta idéia é corroborada por MILLER3 ao afirmar que "O custo tem um significado muito especial em Economia, não apenas quando nos referimos à teoria da firma mas também quando nos referimos à tomada de decisões do consumidor. $\mathrm{O}$ custo em economia significa apenas uma coisa - o custo de oportunidade".

LEFTWICH4 apresenta usos alternativos de um fator de produção e explica que "o custo de uma unidade de qualquer recurso usado por uma firma é o seu valor em seu melhor uso alternativo. Este princípio é denominado, algumas vezes, como o principio do custo alternativo e outras vezes como o principio do custo de oportunidade".

MEYERS5 afirma que "Custo de produção de qualquer unidade de uma mercadoria é o valor dos fatores de produção empregados na obtenção desta unidade - o qual se mede pelo melhor uso alternativo que se poderia dar aos fatores se aquela unidade não tivesse sido produzida". Além disso, o autor chama a atenção de que o custo de oportunidade nem sempre se constitui de dinheiro. Por exemplo, se o dono do capital administra o seu empreendimento, ele deverá computar no custo do produto. o salário que poderia ganhar como gerente de outra empresa similar.

A abordagem do custo de oportunidade por SPENCER \& SIEGELMANN6 não difere dos demais autores da 'área econômica. Eles afirmam que "o custo alternativo se refere ao custo das oportunidades a que se renuncia, ou em outras palavras, uma comparação entre a política que se elegeu e a que se abandonou. Por exemplo, o custo do capital investido é o juro que se pode ganhar no melhor uso seguinte com um risco igual.

\footnotetext{
${ }^{2}$ BILAS. Richard A. Teoria Macroeconômica: uma análise gráfica. 5 ed. Rio de Janeiro, Forense-Universitária, 1976. p. 168

${ }^{3}$ MILLER, Roger Leroy. Microeconomia: teoria, questão. e aplicações. São Paulo, McGraw-Hitl do Brasil, 1981. p.188.

${ }^{4}$ LEFTWICH, RIchard H. Introductfon to microeconomics. Meia York, Holt, Renehart and IImton, 1970. p. ๆ23.

${ }^{5}$ MEYERS, Albert L. Elementos de economia moderna. 4, ad. Rio de Janeiro, Livro Ibero-Americano, 1960. p. 107-109.

${ }^{6}$ SPENCER, Ntttan N. \& SIEGELMAN, Louls. Economia de la administración de empresas. México, Union Tipografia Editorial Hispano Americana, 1967. p. 293-294.
} 
DEAN7 refere-se a este tema da seguinte forma: "Custos de oportunidades tomam a forma de lucros originários de riscos alternativos que são superados pelo uso de vantagens limitadas por um propósito particular. Uma vez que representam somente alternativas sacrificadas, nunca são registrados como tais nas contas financeiras". Os pontos de vista sobre o custo de oportunidade, expressos pelos autores citados, evidenciam uma certa congruência de opinião no que concerne à determinação do valor do custo de oportunidade.

Isto é, o custo de oportunidade não depende de quem está usando estes recursos. Assim, o custo de oportunidade de uni fator de produção de unia empresa não á apenas seu melhor uso alternativo interno, mas também o valor de seu melhor uso alternativo fora da empresa.

Portanto, na abordagem econômica, o valor do custo de oportunidade dos fatores de produção é buscado no mercado. Desse modo, sempre que ocorrer o deslocamento dos fatores de produção de urna para outra atividade, na visão econômica, o mercado desempenhará importante papel na determinação do seu custo de oportunidade.

\section{CONCEITUAÇÁO CONTÁBIL DO CUSTO DE OPORTUNIDADE}

Entre os autores da área contábil-financeira que expressam seus pontos de vista acerca do custo de oportunidade, verifica - se uma maior objetividade na enunciação das conceituações, possuindo no entanto algumas diferenças na terminologia empregada.

MARTINS8, no início do capitulo sobre custo de oportunidade, comenta a aplicabilidade deste conceito, a saber: "Este é um conceito costuineiramente chamado de 'econômico' e 'nãocontábil', o que em si só explica, mas não justifica, o seu não muito uso em Contabilidade Geral ou de Custos". Referindo-se ao aspecto conceitual ele diz que "representa o Custo de Oportunidade o quanto a empresa sacrificou em termos de remuneração por ter aplicado seus recursos numa alternativa ao invés de em outra".

Para BENKE JR.9 o custo de oportunidade é definido "como a medida do sacrifício feito na forma de oportunidades possíveis no sentido de seguir um particular curso de ação".

Segundo DICKEY10, custo de oportunidade "é a medida do benefício previsto como resultado da rejeição de unia alternativa do uso de recursos".

GRAY \& JOHNSTON 11 afirmam que "um custo de oportunidade é o lucro que poderia ter sido conseguido se uni conjunto de recursos tivesse sido aplicado num certo uso alternativo".

Depreende-se dos quatro conceitos apresentados que duas expressões foram utilizadas para caracterizar custo de oportunidade. MARTINS \& BENKE JR. referem-se à medida do "sacrifício" feito pela empresa pela aplicação de seus recursos numa alternativa. Enquanto que DICKEY e GRAY \& JONHSTON reportam—se ao "beneficio/lucro" que poderia ter sido obtido.

Nesse sentido, HORNGREN ${ }^{12}$ conceitua o custo de oportunidade de modo mais abrangente. Ele diz que "o custo de oportunidade é o sacrifício mensurável da rejeição de uma

\footnotetext{
${ }^{7}$ DEAN, Jo.I. Economia de empresas. Rio de Janeiro, Fundo de Cultura, 1968. p. 352.

${ }^{8}$ MARTINS, Eliseu. Contabilidade de custos 3 ad. São Paulo, Atlas, 1967. p. 234.

${ }^{9}$ BENKE Jr., Ralph L. \& EDWARDS, James Don. Transfer pricing.: techniques and uses. Neta York, National Association of Accountants, 1960. p. 50.

${ }_{11}^{10}$ DICKEY, Robert 1. Accountants cost handbook New York, Ronald Press• 1967. p. 1.11.

${ }^{11}$ GRAY, Jack \& JOHNSTON, Kennth. Contabilidade e administração SI. Paulo, McGraw-Hill do Brasil, 1977. p. 162.
} 
alternativa; é o montante máximo sacrificado pelo abandono de urna alternativa; é o lucro máximo que poderia ter sido obtido se o bem, serviço ou capacidade produtivos tivessem sido aplicados a outro uso operacional".

Um outro aspecto que fica evidenciado é que a mensuração do custo de oportunidade de uma alternativa tem como parâmetro alguma característica da alternativa abandonada. Isto pode ser averiguado na conceituação de BACKER \& JACOBSEN ${ }^{13}$ (13): "um custo de oportunidade é o custo resultante de uma alternativa à qual se tenha renunciado".

Contudo, em se tratando da mensuração do custo de oportunidade, permanece uma ausência de consenso na literatura sobre a palavra que deve ser empregada:

beneficio, lucro, recebimento liquido de caixa, custo etc. Acredita-se que estas divergências podem ser atribuídas a duas questões básicas: o correto entendimento do que é custo de oportunidade e a dificuldade de operacionalizar o conceito em toda a sua amplitude.

LEININGER ${ }^{14}$ (14), com o intuito de resolver este problema, propõe duas conceituações operacionais para o custo de oportunidade. Uma para situações de lucro e outra para situações de custos. Para o primeiro caso ele sugere a seguinte definição operacional: "Custo de oportunidade - (Situação de Lucro) é a diferença entre o lucro se for aplicada a política correta e o lucro resultante da política adotada". Enquanto que para a segunda situação o referido autor sugere a seguinte definição operacional: "Custo de oportunidade (Situação de Custo) é a diferença entre o custo incorrido e o custo que poderia ter sido incorrido se a política correta tivesse sido adotada".

O atributo escolhido por MORSE \& ROTH15 para mensurar o custo de oportunidade é o recebimento liquido de caixa. eles afirmam que "o custo de oportunidade do uso de um recurso de uma maneira é o recebimento líquido de caixa esperado que poderia ser obtido se o recurso fosse usado na outra ação alternativa mais desejável".

FIEDMAN \& NEUMANN16 apresentam um conceito similar, dizendo que, "custo de oportunidade reflete a oportunidade prevista para receber algum fluxo de caixa positivo".

Do que até aqui exposto observa-se, pois, que o conceito de custo de oportunidade, tanto em Economia quanto em contabilidade, tem fundamento a escolha entre alternativas viáveis de aplicação de recursos.

Todavia, a nível de implementação de conceito de custo de oportunidade no processo decisório das empresas, encontram-se dificuldades na determinação de um único atributo para as diversas alternativas bem como a mensuração das mesmas. Muitas vezes, estes valores não são obteníveis de imediato no mercado e projeções (estimativas) devem ser efetuadas.

\section{CUSTOS DE CAPITAL}

O custo de capital é um dos assuntos que tem recebido muita atenção na literatura financeira dos últimos anos. Segundo $\operatorname{LEME}^{17}$ houve duas razões principais para essa ênfase. Em

12 (12) HORNGREN, Chartes 7. Contabilidade de custos: tm unfa .m adeinietrativo. Lia Paulo, Atlas, 1986. V. 1. p. 528.

${ }^{13}$ BACKER, Morton \& JACOBSEN Lyle E. Contabilidade de custos: uma abordagem gerencial. 2 ad. São Paulo, McGraw-Hill, 1984. p. 10.

14 LEIWINGER, Wayne E. Opportunity cost: some definitions and examples. The accounting Review. 52(1) 248-251, january, 1977. p. 249 e 251.

${ }^{15}$ MORSE, Wayne \& ROTH, Harold P. Cost accounting: processing, evaluating and using cost data. 3 ad. Reading, Massachusetts, Addison-Wesley Publishing, 1986. p. 36-37.

${ }^{16}$ FRIEDMAN, Laurance \& NEUMANN BRUCE R. The effects of opportunity costs on project investiment decisions: a replication and extension. Journal of Accounting Research. 18(2): 407-419. Autum, 1980. p. 407.

Caderno de Estudos nº8, São Paulo, FIPECAFI - Abril/1993 
primeiro lugar, foi reconhecida a importância do conceito de custo de capital como um fator vital na tomada de decisão financeira da empresa. Em resumo, é ele um conceito difícil de ser definido, e sobre o qual existe uma grande divergência de opiniões.

Continuando, o referido autor explica que o modo específico pelo qual o custo de capital é usado, geralmente como critério de aceitação, depende do método de avaliação selecionado. No método de taxa de retorno, o custo de capital é, normalmente, utilizado como um ponto-limite ou taxa limite. Todos os projetos com taxas de retorno superiores ao custo de capital são, presumivelmente, aceitáveis, enquanto que os com menores taxas de retorno devem ser rejeitados. No método do valor presente líquido, o custo de capital é utilizado com a taxa de desconto aplicada nos fluxos de caixa do projeto analisado. Se o projeto assim descontado tem um valor presente liquido positivo, ele deve ser aceito. Se seu valor presente liquido for negativo, quando descontado ao custo de capital, isto significa que ele não cobrirá seus custos de financiamento e deve ser rejeitado.

Esses métodos de utilização do custo de capital podem levar, algumas vezes, a decisões incorretas, devido aos pressupostos dos métodos de taxa de retorno e do valor presente líquido, especialmente em relação ao reinvestimento ou financiamento dos fluxos intermediários de caixa.

\subsection{Anatomia dos Custos de capital}

O custo de capital compõe-se de diversos elementos. Um deles foi denominado por PORTERFIELD ${ }^{18}$ de custo explícito de capital. O custo explicito de qualquer fonte de capital é"a taxa de desconto que iguala o valor presente das entradas de caixa incrementais a serem geradas pela aceitação da proposta de financiamento com 0 valor presente das saídas de caixa incrementais. Isto é o mesmo que a taxa de desconto que torna o valor presente de todos os futuros fluxos de caixa ligados à fonte igual à entrada inicial que ela propicia".

Portanto, os custos explícitos foram definidos como sendo a taxa de desconto que iguala o influxo inicial de caixa provindo de uma fonte de fundos ao valor presente dos fluxos de caixa subseqüentes, associados a essa fonte.

Observa-se pelo exposto que, até esse momento, a preocupação foi com a determinação do custo explícito do capital no contexto do processo decisório de investimentos. Em nenhum ponto foram consideradas as oportunidades que podem existir para a utilização dos fundos em questão. São essas outras oportunidades que dão origem aos custos iniplicitos de capital.

O custo implícito de capital dos fundos levantados e investidos pela empresa pode ser definido como a taxa de retorno do melhor projeto da empresa, da melhor oportunidade de investimento do acionista ou da melhor oportunidade de consumo acionista que seria abandonada, se o projeto, ora em consideração pela firma, fosse aceito.

Ressalte-se que os custos explícitos de capital surgem quando os fundos são levantados. Os custos implícitos de capital só aparecem quando os fundos são investidos ou utilizados de outra forma. Isso deve-se ao fato de eles representarem usos alternativos para os fundos em questão.

\footnotetext{
${ }^{17}$ LENE. Thoz de Aqjtno Gapcez. Custo de oaorttnidad. do caoital. Lia Pauto, FEA/USP, Círculaçio Interna, 1991. p. 2230.

${ }^{18}$ PORTERFIELD, James T. S. Decisões de Investimento e custo de capital. 1 ad. Lia Paulo. Atlas, 1976.
} 


\subsection{Custo de Oportunidade do Capital Próprio}

Em temos gerais a estrutura de financiamento de urna empresa compreende seu passivo e seu patrimônio liquido. Esse lado direito do balanço indica de onde provêm os fundos para financiar os saldos existentes dos recursos do ativo. Mas para se avaliar o rendimento dos investimentos atuais e futuros é necessário compará-los com o custo relativo dos recursos financeiros que os tornaram possíveis.

MEPHAN ${ }^{19}$ evidencia a necessidade de utilização do custo de oportunidade em detrimento dos custos explícitos tradicionais. O autor explica que a dificuldade fundamental é que tem sido assumido que os benefícios são adições e os custos são deduções do valor de uni único objetivo, o lucro.

Entretanto, existem de fato múltiplos objetivos conflitantes, tais como crescimento, liquidez, -dividendos, entre outros. Desse modo, assim como o resultado de um dado programa pode ser benéfico em relação a determinado objetivo, ele pode inibir ou dificultar o alcance de outros objetivos.

Neste sentido, ANTHONY ${ }^{20}$ parece conseguir uma aproximação maior do conceito de custo de oportunidade utilizado no campo econômico e o passível de aplicação na área contábil. A solução conciliatória do referido autor, a nível operacional, se baseia nos seguintes pressupostos:

a) o custo de oportunidade dos recursos de terceiros já é reconhecido no momento em que a contabilidade registra os custos históricos desses recursos; e

b) para capitais próprios, como a contabilidade tradicional não reconhece o custo dos mesmos, passaria a utilizar-se o conceito de custo de oportunidade.

Infere-se pelo exposto que o autor mencionado preconiza a utilização dos juros sobre o capital próprio. Todavia, essa é uma simplificação do uso do custo de oportunidade na contabilidade que pressupõe que todos esses recursos estão materializados num único ativo, o que normalmente não acontece.

A questão que se coloca nesta alternativa de uso do custo de oportunidade é como operacionalizar a aplicação de uma taxa de juros sobre o capital próprio?.

\subsubsection{Metodologia a ser Utilizada}

Nesta seção pretende-se discutir uma metodologia para a determinação dos juros sobre capital próprio, em termos de taxas e base de cálculo.

Raciocinando que os juros sobre o capital próprio dizem respeito aos recursos que uma empresa possui é preciso que as taxas alternativas de juros também sejam consideradas apenas no âmbito das possibilidades de aplicação do capital próprio pela empresa.

Neste sentido, SCHLATTER \& SCHLATTER ${ }^{21}$ dizem que "a taxa usualmente selecionada é aquela pela qual o dinheiro poderia ser emprestado na região com uma razoável segurança do principal".

\footnotetext{
${ }^{19}$ MEPHAN, M. J. Opportunity cost and the accountant. Journal of the Institute of Cost and Management Accountants. May; 1981. p. 39-1.1

${ }^{20}$ ANTHONY, Robert N. Accounting for the cost of equity. Harvard Business Review. November-December, 1973. p. 89-90.

${ }^{21}$ SCHLATTER, C. F. \& SCHLATTER, W. J. Cost accounting. 2. ed. New York, John Wiley \& Sons. Inc.1957. p. 705.
} 
Para a determinação dos juros sobre o capital próprio, HANSEN ${ }^{22}$ propõe usar um tipo de juro que mais ou menos corresponda ao que, normalmente se deve pagar para obter dinheiro do mercado.

GUERREIRO \& SPERANDIO ${ }^{23}$ fazem a seguinte indagação:

"Existe comparabilidade conceitual entre a taxa de juros sobre o capital próprio e a taxa de juro do mercado financeiro?". Eles respondem a sua indagação dizendo que o cálculo do juro sobre o capital próprio pode corresponder ao custo de oportunidade do desempenho econômico em uni determinado período, aceitando-se a premissa que uni uso alternativo dos fatores de produção de uma empresa é a sua venda, e que o lucro nesse uso alternativo corresponde à aplicação desse montante no mercado financeiro a uma taxa de risco mínimo".

De imediato observa-se que a aceitação de equivalência conceitual, entre a taxa de retorno sobre o patrimônio liquido e a taxa de retorno de aplicação no mercado financeiro só é possível se for considerado, além da venda, um único uso alternativo do recurso disponível que é a aplicação no mercado financeiro. Isto, na prática, pode não ser verdadeiro.

ANTHONY ${ }^{24}$ preconiza uma outra metodologia a ser adotada como segue: "na maioria das vezes, custos de juros podem ser determinados para ativos produzidos através de uma única taxa percentual, que corresponde ao custo médio ponderado dos capitais próprios e de terceiros".

Para a determinação dos juros sobre o capital próprio, o referido autor toma por base os percentuais de participação dos capitais próprios e de terceiros em relação ao total das origens de recursos. Em seguida, supondo conhecida a taxa de juros dos capitais de terceiros, sobre ela aplica o percentual encontrado para os recursos de terceiros, o que ele denomina de custo ponderado dos capitais de terceiros. Este custo é subtraido da taxa média do custo dos capitais totais (o autor não apresenta uma metodologia para estimar esta taxa), a fim de obter o custo ponderado dos capitais próprios. Dividindo este custo pelo percentual de participação dos capitais próprios em relação ao capital total, anteriormente obtido, chega-se á taxa de juros sobre o capital próprio. A seguir é dado o exemplo desse cálculo.

Supondo-se: a empresa possui a seguinte estrutura de capital: $40 \%$ recursos de terceiros e $60 \%$ de capital próprio. A taxa de juros dos capitais de terceiros é de $45 \%$ e o custo dos capitais totais da empresa é de $60 \%$. Para determinar os juros sobre o capital próprio, procede-se da seguinte forma:

\begin{tabular}{|l|l|l|l|}
\hline Recursos & $\%$ Partic & Tx.do juros & $\begin{array}{l}\text { Custo Ponder. dos } \\
\text { Capitais }\end{array}$ \\
\hline Terceiros & 40 & $45 \%$ & $18 \%$ \\
\hline Próprios & 60 & $70 \%\left(^{*}\right)$ & $42 \%$ \\
\hline Totais & 100 & -- & $60 \%$ \\
\hline \multicolumn{2}{|r|}{$\begin{array}{l}\text { * [(Custo ponderado dos capitais totais - custo ponderado dos recursos de terceiros }) / \\
\text { pelo \% de participação do capital próprio) }=((60 \%-18 \%) / 60 \%]=70 \%\end{array}$}
\end{tabular}

Depreende-se pelo exposto que existem divergências quanto à taxa de custo de juros do capital próprio que a empresa deve utilizar. Todavia, é preciso estar ciente que as taxas a serem praticadas terão um grande viés do risco que os tomadores de decisão estarão dispostos a assumir, diante das diversas alternativas possíveis de aplicação dos recursos.

\footnotetext{
${ }_{22}^{2}$ HANSEN. Palle. Contabilidade interna de la industria. - Madrid, Aguabar, 1957. p. 89.

${ }^{23}$ GUERREIRO, Reinaldo \& SPERANDIO, Olivio. Contabilização do custo de oportunidade. São Paulo, FEA/USP, Trabalho apresentado na disciplina Teoria da Avaliação Patrimonial, 1985. p. 1.2.

${ }^{24}$ ANTONY, Robert N. Op. cit. p. 92-93.
} 


\subsubsection{Tratamento Contábil}

$\mathrm{Na}$ literatura sobre custo de oportunidade, observa-se que as abordagens a nível de contabilização vão de encontro ao conceito de custo de oportunidade, distanciando-se do conceito original. As aplicações contábeis restringem-se a situações especificas e mais recentes de contemplar o custo de oportunidade, tais como juros sobre o capital próprio.

DRIMER \& RODRIGUEZ NIETO25 defendem a contabilização dos juros sobre o capital próprio e apresentam como argumentos o que segue:

- $\quad$ a massa de riqueza (patrimônio liquido) que está \& disposição das empresas e é manipulada por seus administradores, será maior;

- $\quad$ maior geração de recursos próprios por parte das empresas, devido a:

a) menor pagamento de dividendos aos acionistas;

b) menor pagamento de imposto sobre lucros;

- $\quad$ o índice de liquidez corrente aumenta;

- melhoria da solvência, medida pelo índice de endividamento, devido ao maior patrimônio liquido contábil;

- redução dos lucros disponíveis e distribuíveis".

Entretanto, eles concluem o seu artigo afirmando que o conceito de juros sobre o capital próprio e a sua contabilização são convenientes para os usuários internos. Para.os usuários externos não é aconselhável a adoção dessa metodologia.

ANTHONY26 também se posiciona favorável à efetiva contabilização dos juros sobre o capital próprio. Ele ilustra o registro da seguinte forma:

JUROS REAIS E IXPUTADOS (INTEREST POLL)

\begin{tabular}{|l|c|c|c|}
\hline $\begin{array}{c}\text { Juros s/Capital } \\
\text { de Terceiros }\end{array}$ & $\$ 10$ & Custo das & $\$ 23$ \\
\hline $\begin{array}{c}\text { Juros s/Capital } \\
\text { Próprio }\end{array}$ & $\$ 30$ & Estoque & $\$ 8$ \\
\hline & & Imobilizado & $\$ 4$ \\
\hline & $\$ 40$ & Diversos & $\$ 5$ \\
\hline
\end{tabular}

O valor inicial dos juros sobre o capital de terceiros foi de $\$ 20$. Deste foi expurgado o imposto de renda de $\$ 10$, cuja contrapartida é lançada numa conta de resultado, denominada Aiustamento Fiscal. Este procedimento se justifica para compensar o ganho fiscal relativo, visto que esta despesa é dedutível, enquanto que os juros sobre os capitais próprios não o são.

O saldo devedor da conta Juros Reais e Imputados é zerado com os seguintes créditos:

\footnotetext{
${ }^{25}$ DRIMER, Roberto L. \& RODRIGUEZ NIETO, Manuel. Contabilizacion del costo de capital próprio. Administración de Empresas. Argentina, 15(179): 841-851, Febrero, 1985. p. 8/.6.

${ }^{26}$ ANTHONY, Robert N. Op. cit. p. 94.
} 
a) Como custo de produção do período foram imputados $\$ 31$. Pela venda dos estoques foram transferidos para custo das vendas $\$ 23$. O valor restante, $\$ 8$, foi para o estoque;

b) Foram imputados $\$ 4$ para o imobilizado e;

$\$ 5$ foram transferidos para despesas gerais.

Desse modo:

\begin{tabular}{|cl|l|}
\hline \multicolumn{2}{|c|}{ o resultado do exercício diminuiu } & $\$ 18$ \\
\hline$(+)$ & Ajustamento Fiscal & $\$ 10$ \\
\hline$(-)$ & Custo de Vendas & $\$ 23$ \\
\hline$(-)$ & Despesas Gerais & $\$ 5$ \\
\hline$(=)$ & Redução do Lucro Líquido & $(\$ 18)$ \\
\hline
\end{tabular}
imobilizado.

Adicionalmente, verifica—se uni acréscimo de $\$ 12$ no ativo e $\$ 8$ nos estoques e $\$ 4$ no

A partir de então, falta explicitar as contra-partidas credoras dos débitos iniciais na conta Juros Reais e Imputados ("Interest Pool"). Os juros sobre os capitais de terceiros (\$20) são acrescidos aos passivos ou creditados no ativo (disponibilidades).

A contra-partida dos juros sobre os capitais próprios (\$30), de acordo com o autor, pode ser feita em uma conta especial do Patrimônio Liquido ou na própria conta Lucros Acumulados.

Observa-se então, que o acréscimo feito no patrimônio líquido é compensado com a redução do lucro do exercício (S 18) e o aumento do ativo (\$12).

A proposta do autor tem subjacente o conceito de resultado econômico, visto que imputa nos ativos os juros sobre o capital próprio. Este é, sem dúvida, um avanço em relação aos procedimentos de avaliação dos ativos utilizados pela contabilidade tradicional.

SCHLATTER \& SCHLATTER27 concordam com as aplicações do custo de oportunidade, mas o procedimento do registro dos juros sobre o capital próprio que propõem acaba não afetando o resultado da empresa. Além disso, a base de cálculo, para a determinação dos juros sobre o capital próprio são os ativos fixos. Os autores justificam este procedimento devido a dificuldades operacionais de fazer incidir os juros sobre os demais ativos. Porém, eles reconhecem que isto é unta simplificação e que tais juros deveriam ser imputados a todos os ativos.

Infere-se pelo exposto que existem duas diferenças substanciais entre as propostas de "Anthony" e "Schlatter \& Schlatter". A primeira diferença consiste em aquele autor apresentar uma proposta de contabilização dos juros sobre o capital próprio que acaba por afetar os resultados finais da empresa. Enquanto que estes últimos propõem uma metodologia em que os juros incluídos nos estoques acabam não se refletindo no resultado final do exercício, devido a ajustes.

A segunda diferença consiste na base de cálculo. "Anthony" calcula os juros sobre o capital próprio fazendo incidir os juros apenas sobre o capital dos sócios, por entender que os juros não devem incidir sobre o capital da entidade formado pelo excesso de lucros originados da operação. Já, "Schlatter \& Schlatter" utilizam como base de cálculo do juro sobre o capital próprio somente os ativos fixos.

${ }^{27}$ SCHLATTER, C. F. \& SCHLATTER, W. J. Op. cit 


\subsubsection{Legislação Brasileira}

No que concerne às práticas atuais no Brasil em relação à contabilização dos juros sobre o capital próprio, MARTINS, na IOB,(28) através do Boletim 15/83/28(28) se manifesta da seguinte forma:

"Como regra geral não são passíveis de contabilização os juros sobre o capital próprio. Ou seja, a empresa não pode registrar os juros que seriam devidos ao patrimônio líquido como se esses recursos dos sócios pudessem receber tal remuneração. (...)

Não admite essa contabilização a título de regra, mas há uma grande exceção, tanto em termos de teoria contábil, de doutrina, como, de aplicação prática e até de legislação especifica."

Trata—se de quando a empresa está ainda na fase pré-operacional".

A contabilização, para quem quiser, do juro sobre o capital, nessa fase, está prevista na Lei n 6.404/76, em seu artigo 179, item V. a saber:

"No ativo diferido: as aplicações de recursos em despesas que contribuirão para a formação do resultado de mais de um exercício social, inclusive os juros pagos ou creditados aos acionistas durante o período que anteceder o início das operações sociais".

A legislação fiscal também é explícita sobre o assunto. De acordo com o artigo 109 do RIR (Decreto $n$ 85.450/80) é admitida a dedutibilidade da amortização desses juros, como segue: "Poderão ser amortizados: ... II ... g) os juros pagos ou creditados aos acionistas durante o período que anteceder o inicio das operações sociais, ou de implantação do empreendimento inicial (Decreto Lei n0 1.598/77, art. 15, parágrafo 10, b)".

Outras exceções de contabilização dos juros sobre o capital próprio ocorrem na área de Serviços Públicos, mais especificamente, no setor de Energia Elétrica e na Telefonia. A legislação especifica dessas concessionárias permite a contabilização dos juros sobre o capital próprio não somente quando a empresa toda está em fase pré- operacional mas, também, quando apenas parte dela o está.

No que concerne aos serviços de energia elétrica o Decreto 41.019, de 26-12-1957, em seu artigo 159, parágrafo 20., estabelece o seguinte:

"A parte do investimento de obras em andamento, realizada com capital próprio, vencerão juros iguais à taxa de remuneração fixada para o investimento remunerável, até a data da entrada em serviço das instalações, juros esses que serão capitalizados e acrescidos ao custo das obras".

No que se refere às concessionárias de serviços de telefonia, a portaria 1381 de 28-121978, do Ministério das Comunicações, em seu artigo 9, parágrafo 30, determina o que segue:

"os investimentos em obras em andamento vencerão juros de $12 \%$ (doze por cento) a.a, até a data da entrada em serviço das instalações. A partir deste momento, os juros respectivos deverão ser amortizados no prazo de 10 (dez) anos. A parcela de juros sobre obras financiadas por capitais próprios, caracterizada como reserva de capital, será creditada ao patrimônio liquido e utilizada conforme dispõe o artigo 200 da Lei 6.404/76 e seus parágrafos".

${ }^{28}$ MARTINS, Eliseu. Bol. 15/83, Temática Contábil e Balanços. Juros sobre capital próprio. p. 155-159 
Por exemplo, supondo-se que unia concessionária de serviços de telefonia apresente a seguinte situação:

BALANÇO PATRIMONIAL EM TO

\begin{tabular}{|c|c|c|c|}
\hline ATIVO & & \multirow{5}{*}{$\begin{array}{l}\text { PASSIVO } \\
\text { EXIGIIVEL A LONGO PRAZO } \\
\text { Empréstimos } \\
\text { PATRIMÔNIO LÍOUIDO } \\
\text { Capital Social }\end{array}$} & \\
\hline \multirow{5}{*}{$\begin{array}{l}\text { PERMANENTE } \\
\text { Investimentos } \\
\text { Obras em Andamento }\end{array}$} & \multirow{4}{*}{\begin{tabular}{c}
$\$ 1.000$ \\
\hdashline$\$ 1.000$
\end{tabular}} & & \\
\hline & & & $\$ 700$ \\
\hline & & & \\
\hline & & & $\$ 300$ \\
\hline & & & $\$ 1.000$ \\
\hline
\end{tabular}

Além disso, que durante o período $\mathrm{Ti}$, nenhuma atividade tivesse sido realizada pela concessionária.

Assim, no final do período, devem ser imputados os juros sobre os capitais que financiaram as obras em andamento. Supondo-se que sobre os investimentos em obras, com recursos de terceiros, vencem juros de $15 \%$ a.a., o balanço patrimonial configuraria-se do seguinte modo:

\section{BALANÇO PATRIMONIAL EX T1}

\begin{tabular}{|c|c|c|c|}
\hline \multirow{6}{*}{$\begin{array}{l}\text { ATIVO } \\
\text { PERMANENTE } \\
\text { Investimentos } \\
\quad \text { Obras em Andamento } \\
\text { Diferido } \\
\text { Juros s/Obras em And. } \\
\text { Desp. Financ. Diferidas }\end{array}$} & & \multicolumn{2}{|l|}{$\begin{array}{l}\text { PASSIVO } \\
\text { FXIGÍVIFI AI ONGO PRA7O }\end{array}$} \\
\hline & \multirow{3}{*}{$\$ 1.000$} & $\begin{array}{l}\text { EXIGÍVEL A LONGO PRAZO } \\
\text { Empréstimos }\end{array}$ & $\$ 700$ \\
\hline & & PATRIMÔNIO LÍOUIDO & \\
\hline & & Capital Social & $\$ 300$ \\
\hline & $\$ 120$ & Reserva de Capital & \\
\hline & $\$ 21$ & Res.Esp.Juros Obras & $\$ 36$ \\
\hline & $\$ 1.141$ & & $\$ 1.141$ \\
\hline
\end{tabular}

Ressalte-se que os juros sobre os recursos de terceiros foram segregados em "Juros s/Obras em Andamento" (12\% a.a.) e "Despesas Financeiras Diferidas" (o restante). Esta contabilização é útil para a determinação do valor da tarifa, visto que os juros excedentes a $12 \%$ a.a. não podem ser computados nos preços dos serviços da concessionária.

Do que está até agora dito, conclui-se que a legislação brasileira permite a contabilização dos juros sobre o capital próprio apenas em algumas situações. Contudo, muitas empresas incluem esse juro em sua planilha de custos para fazer a precificação dos produtos ou serviços.

\section{CONCLUSÃO}

Pelo desenvolvimento do presente artigo pode-se observar que o conceito do custo de oportunidade encontra-se bastante difundido no campo econômico. Esta mesma disseminação não é encontrada na área contábil. 
Contrapondo-se o modo pelo qual o conceito de custo de oportunidade é concebido pelos economistas e pelos profissionais da área contábil, observa-se que não é permitido aos últimos incorporarem à contabilidade, na sua forma original, o conceito que lhe é atribuído por aqueles.

O ponto básico das divergências reside nos princípios subjacentes ao conceito do custo de oportunidade e os que regem a contabilidade. De acordo com a visão econômica, o custo de oportunidade deve ser registrado a valores de saída. Já, na contabilidade, o principio do custo como base de valor determina que os ativos sejam registrados a valores de entrada. Além disso, pode ser invocada a questão da mensuração subjetiva do custo de oportunidade, no campo econômico. A contabilidade, por sua vez, prima pela objetividade, especialmente quando se trata de relatórios externos.

Um outro aspecto que deve ser considerado refere-se aos conflitos existentes entre os próprios contadores sobre o custo de oportunidade. Estas diferenças se estendem desde 0 aspecto conceitual até a operacionalização do conceito.

A nível conceitual, não existe uniformidade quanto ao termo que deve ser empregado para representar o atributo quantitativo do custo de oportunidade (valor, benefício, lucro, recebimento liquido de caixa, custo etc.).

Do ponto de vista operacional, os autores da área contábil são concordes que considerar os juros sobre o capital próprio como um custo de oportunidade é uma forma específica (simplificada) de contemplar o assunto. Entretanto, diferenças de opinião são encontradas sobre a taxa de juros e a base de cálculo a ser utilizada.

No que se refere à taxa de juros a ser aplicada, existem, basicamente, duas opiniões: taxa de juros do mercado financeiro e taxa de juros do custo de capital.

Em tratando da base de cálculo, os autores divergem entre aplicar a taxa de juros sobre o patrimônio líquido, o capital social ou itens específicos do ativo.

Ressalte-se, finalmente, que existem diferentes interpretações no que concerne à contabilização dos juros sobre o capital próprio. A proposta mais arrojada foi observada em Anthony, que fez refletir nos resultados finais (patrimônio líquido) os juros apropriados aos estoques.

Apesar do tratamento dado, gerencialmente, ao custo de oportunidade e até mesmo à sua forma especifica de aplicação (juros sobre o capital próprio), parece persistirem dúvidas sobre a importância da contabilidade societária registrar tais valores.

Provavelmente, as empresas, a nível de contabilidade interna, já vêm implementando diferentes registros do custo de oportunidade. Neste sentido, nada impede que esforços sejam enviados para uni reconhecimento gradativo, pela contabilidade, dos custos de oportunidade para efeitos de relatórios externos. 